\title{
Anti-inflammatory Compounds Camphor and Methylsalicylate from Traditionally Used Pain Curing Plant Equisetum arvense $L$.
}

\author{
Achyut Adhikari ${ }^{1 *}$, Silan Bhandari ${ }^{1}$, Durga Prasad Pandey ${ }^{2}$ \\ ${ }^{1}$ Central Department of Chemistry, Tribhuvan University, Kirtipur, Kathmandu, Nepal \\ ${ }^{2}$ Research Centre for Applied Science and Technology (RECAST), Tribhuvan University, Kirtipur, Kathmandu, Nepal \\ *Corresponding E-mail: adhikarimine@yahoo.com \\ (Received: Sept. 11, 2019; Revised: Dec. 25, 2019 \& Accepted: Dec. 27, 2019)
}

\begin{abstract}
Equiseum arvense $L$. is a bushy perennial herb commonly called field horsetail distributed in the northern part of Nepal and used against curing muscle and bone pain and other many diseases. This research work was performed to analyze the possible cause of the anti-inflammatory activity of this plant. Out of four different fractions, dichloromethane (DCM ) fraction showed the presence of compounds on TLC and was subjected to column chromatography to isolate and identify pure compounds. $\mathrm{D}_{2}$ and $\mathrm{D}_{20}$ fractions eluted from column gave single and distinguished spots so that these fractions were subjected to gas chromatography analysis. The GC analysis of the pure fraction $\mathrm{D}_{2}$ obtained from column revealed the presence of a major compound major compounds camphor (92.53\%) and other minor compounds; (+)-2-Bornanone, Camphor, Carvone $<(\mathrm{z})$-, dihydro- $>$, Benzoic acid, 2-(1-oxopropyl)- and GC report from $\mathrm{D}_{20}$ fraction showed two compounds; Salicylate $<$ methyl- $>$ and Benzoic acid, 2-(1-oxopropyl)-. The major compounds camphor (92.53\%) and methyl salicylate $(66.87 \%)$ have been reported being potent anti-inflammatory activity and their synergetic effect is more prominent for the same.
\end{abstract}

Keywords: Equisetum arvense, anti-inflammatory, camphor, methyl salicylate.

\section{Introduction}

Equisetum arvense $L$. is the bushy perennial herb, commonly called field horsetail which is usually distributed in the northern hemisphere throughout Canada, USA, Europe, and Asia south to Turkey, Iran, the Himalayas, and across China, Korea and Japan [1]. In Nepal, it is found in moist places of the country at about $2000 \mathrm{~m}$ and commonly known as "Kurkure Jhar".

Horsetail consists of the creeping, string-like rootstock and roots at the nodes that produce numerous hollow, and conspicuously jointed stems. Two different types of the stem; the sterile stems are green bottle brushlike and tend to be much taller and bushier, with the jointed segments being around one inch long with a diameter of about $1 / 20$ th of an inch. The fertile stems are generally half as tall as the sterile stems and also tend to be more succulent. Fertile stems bearing spore clusters at its tip appears in early spring and are usually thick and succulent, brownish to whitish, 10 $-30 \mathrm{~cm}$ tall [2].

In folk medicine, Equisetum arvense is used for tuberculosis, for catarrh in the kidney and bladder regions, as a hemostatic for profuse menstruation, nasal, pulmonary and gastric hemorrhages, for brittle fingernails and loss of hair, for rheumatic diseases, gout, poorly healing wounds and ulcers, swelling and fractures and for frostbite (PDR for herbal medicines) [1]. The commonly known phytochemical compounds in E. arvense are alkaloids, phytosterols, tannin, triterpenoids and phenolics such as flavonoids, styrylpyrones and phenolic acids [3]. Equisetum arvense exhibits a significant antioxidant and antimicrobial activity [4]. The water extract from sterile stems of Equisetum arvense L. has dosedependent cytotoxic effects on human leukemic U 937 cells [5].

FHMDO Monte et al. (2004) experimented on mice 
by applying the hydroalcoholic extract of horsetail to mice which resulted that Equisetum arvense extract has an antinociceptive (pain-relieving) and antiinflammatory agent [6]. Due to the anti-inflammatory action of Equisetum arvense, it is used for arthritis, chilblains, cystitis, gout, inflammation of the lower urinary tract, renal gravel and also for benign enlargement of the prostate gland. Horsetail tea is used as a gargle for mouth and gum inflammation [7]. In Nepal horsetail is used against Burns, scabies, malarial fever (Manandhar 2002, Bhattarai 2007). In the hilly area of Nepal, dried plants of horsetail are pounded and paste is then applied in bone fracture, aches, and pains of the muscles, joints, and backaches [8].

The present study is focused to determine the phytoconstituents of Equisetum arvense and responsible for anti-inflammatory activity.

\section{Materials and Methods}

\section{Collection of plants}

The whole plant of Equisetum arvense was collected from the bank of Ghatte Khola at an altitude of 2000 $\mathrm{m}$ from Siddeswor VDC of Bhojpur district and the collected plant material was identified by D.R. Kandel, 3-5-2019, National Herbarium and Botanical laboratory, (KATH), Godawari, Nepal. The collected plant materials were washed, shade-dried and was ground into powder.

\section{Instruments}

Buchi Rotavapour R-200, Grinder, Digital weighing machine (GT 210), GC-MS-QP 2010 Ultra SHIMADZU, Column Chromatography, water bath (Buchi 461)

\section{Chemicals used}

All reagents and solvents used were of laboratory grade from E. Merck, T. Fisher Scientific, and Qualigens Chemical Companies, India. Solvents used were hexane and dichloromethane (DCM), Silica of 60-120 mesh, Silica gel-G, Pre-coated TLC aluminum plates with a thickness of $0.2 \mathrm{~mm}$.

\section{Extraction process}

Two hundred grams powdered plant was dissolved in $500 \mathrm{~mL}$ of hexane in clean and dry conical flasks and was kept for two days with frequent shaking and the mixtures were decanted and filtered and thus obtained residue was dried and another solvent DCM was added to the dried residue and kept for 2 days with frequent shaking and the mixtures were decanted and filtered. Finally, the obtained filtrates were concentrated with the help of a rotary evaporator below $40{ }^{\circ} \mathrm{C}$. Finally, a semi-solid extract of hexane and DCM extract was obtained.

\section{Isolation of compounds}

DCM soluble fraction was subjected for column chromatography because good separation and a large number of spots were seen in TLC. A slurry of the DCM fraction (1.8 g) was made with a double (1:2) amount of silica gel, which was loaded on to a column packed with silica gel (200 g, E-Merck, 60-120 mesh). The column had an internal diameter of $4.5 \mathrm{~cm}$ and a height of $60 \mathrm{~cm}$. The column was eluted with $100 \%$ hexane at first and then gradually polarity was increased by adding ethyl acetate in hexane with $2 \%$, $3 \%, 4 \%, 6 \%, 10 \%, 15 \%, 20 \%, 25 \%, 30 \%, 35 \%, 40 \%$, $50 \%, 60 \%$ gradients. After obtaining each fraction TLC was checked. The number of spots observed in TLC was visualized under UV-Visible light and iodine chamber. After column chromatography, TLC of each eluted fraction was performed. Fractions having similar TLC were mixed.

\section{Analytic conditions for GC}

The GC-MS analysis was performed at the Department of plant resources, Thapathali and was performed on GCMS-QP 2010 under the following conditions: injection volume $1 \mu \mathrm{L}$ with slit ratio $1: 90$. Helium as a carrier gas with a RTX-5 MS column of dimension 60 $\mathrm{m} \times 0.32 \mathrm{~mm} \times 0.25 \mu \mathrm{m}$, temperature-programmed at 50,150 and $250{ }^{\circ} \mathrm{C}$ with a hold time of 0.0 and 4.0 min identification was accomplished by comparison of retention time with those reported in NIST 2017 and FFNSC 1.3 libraries and test method used was IS O:7609:1985.

\section{Results and Discussion}

The fraction $\mathrm{D}_{2}$ obtained from column chromatography of DCM extract revealed the presence of a major compound camphor $(92.53 \%)$ and other minor compounds $(+)$-2-bornanone $(2.32 \%)$, carvone $<(\mathrm{z})-$, dihydro- $>(0.55 \%)$, and benzoic acid, 2-(1-oxopropyl)(4.59\%). The GC-MS analysis of another fraction $\mathrm{D}_{20}$ revealed the presence of four chemical compounds out of which only two are identified. They are Salicylate $<$ methyl- $>(66.87 \%)$ and Benzoic acid, 
2-(1-oxopropyl)-(21.77\%). Among them, Salicylate $<$ methyl- $>$ is the major component with a percentage area of $66.87 \%$. The results are shown in the table below:

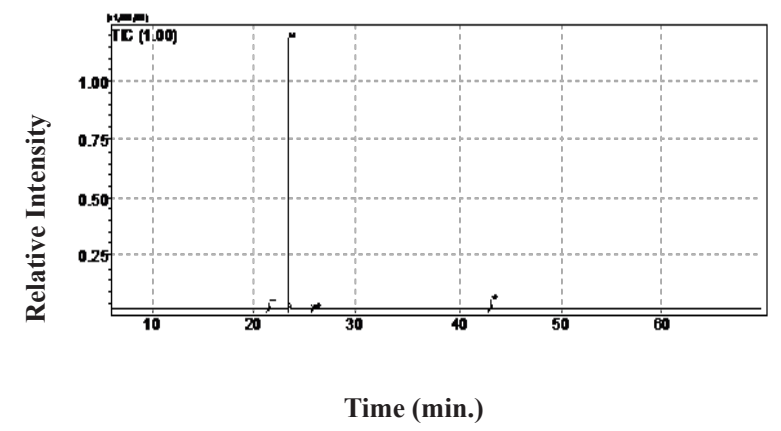

Figure 1: Gas chromatogram of DCM extract $\left(D_{2}\right)$ of Equisetum arvense.
From the above review facts, dry horsetail is traditionally used as a fine powder paste in bone fracture, aches, and pains of the muscles, joints, and backaches. The result of GC showed that DCM extract of Equisetum arvense has a high content of camphor and methyl salicylate that are potent antiinflammatory compounds. The camphor used as OFCMT (Oily formulation of camphor, menthol, and thymol) has shown tremendous protection from pain and inflammation [9] while Multum (2018) reported that methyl salicylate is a nonsteroidal antiinflammatory drug (NSAID) which when used with a combination of camphor and lidocaine works by reducing the substances in the body that cause pain and inflammation and provide temporary relief from aches and pains of the muscles, joints, and backaches.

Table1: Compounds detected in $G C$ analysis of $D_{2}$ fraction of Equisetum arvense.

\begin{tabular}{lllll}
\hline S.N. & \multicolumn{1}{c}{ Compounds } & Retention time (min.) & Percentage area & Molecular weight $(\mathbf{g} / \mathbf{m o l e})$ \\
\hline 1 & (+)-2-Bornanone & 21.530 & 2.32 & 152.23 \\
2 & Camphor & 23.474 & 92.53 & 152.23 \\
3 & Carvone $<$ (z)-,dihydro-> & 25.916 & 0.55 & 152.23 \\
4 & Benzoic acid,2-(1-oxopropyl)- 43.040 & 4.59 & 178.18 \\
\hline
\end{tabular}

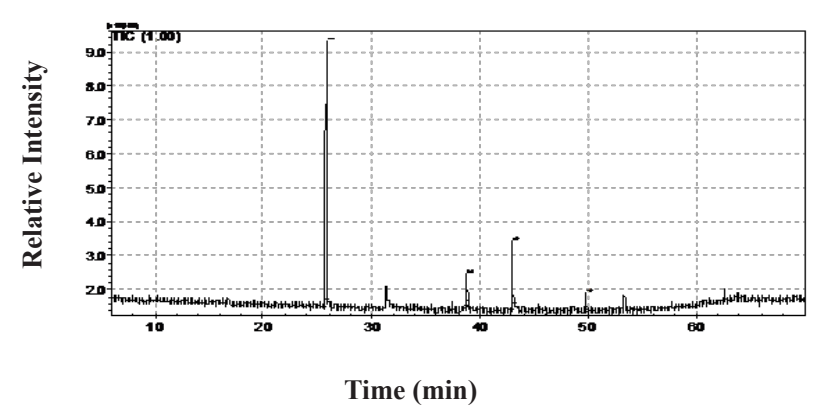

Figure 2: Gas chromatogram of DCM extract $\left(D_{20}\right)$ of Equisetum arvense

Table 2: Compounds detected in $G C$ analysis of $D_{20}$ fraction of the DCM extract.

\section{S.N. Compounds}

1 Salicylate $<$ methyl- $>$

2 Benzoic acid,2-(1-oxopropyl)-

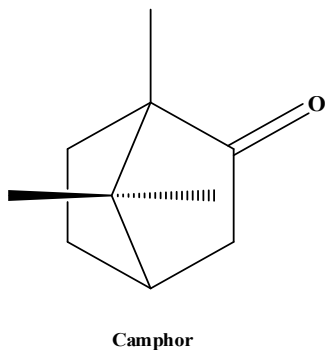

Figure 3: Structure of the major compounds identified by $G C$
Retention time (min.) Percentage area Molecular weight (g/mole)
25.782

42.997
66.87

21.77
152.15

178.18<smiles>COC(=O)c1ccccc1O</smiles> 


\section{Conclusion}

The main compounds that were isolated from DCM extract of Equisetum arvense L. by column chromatography after subjected to FTIR and GC-MS analysis were Camphor (92.53\%) and methylsalicylate $(66.87 \%)$, which are potent antiinflammatory compounds and using them as a mixture is more effective against inflammation. Hence, ethnomedicinal practice of the plant Equisetum arvense to cure pain is scientifically validated.

\section{Acknowledgment}

We are thankful to the Department of Plant Resources, Thapathali, Kathmandu, Nepal for providing a GCMS facility.

\section{References}

1. N. S. Sandhu, S. Kaur and D. Chopra, Equisetum arvense: pharmacology and phytochemistry-a review, Asian Journal of Pharmaceutical \& Clinical Research, 2010, 3, 146-150.

2. A. E. Al-Snafi, The pharmacology of Equisetum arvense -A review, IOSR Journal of Pharmacy, 2017, 7, 31-42.

3. H. J. Altameme, I. H. Hameed and N. A. AbuSerag, Analysis of bioactive phytochemical compounds of two medicinal plants, Equisetum arvense and Alchemila valgaris seed using gas chromatography- mass spectrometry and fourier-transform infrared spectroscopy, Malaysian Applied Biology, 2015, 44, 47-58.

4. Z. Kukrić, L. Topalić-Trivunović, S. Pavičić, M. Žabić, S. Matoš and A. Davidović, Total phenolic content, antioxidant and antimicrobial activity of Equisetum arvense L., Chemical Industry and Chemical Engineering Quarterly/ CICEQ, 2013, 19, 37-43.
5. V. Alexandru, D. N. Petrusca and E. Gille, Investigation of pro-apoptotic activity of Equisetum arvense $L$. water extract on human leukemia U 937 cells, Romanian Biotechnological Letters, 2007, 12, 3139.

6. A. S. Hoque, G. Bithika, N. Rimlee, S. B. Roy, K. Pallab, and D. B. Kumar, Pharmacognostical evaluation and phytochemical screening of the plant Equisetum Arvense L., World Journal of Pharmacy \& Pharmaceutical Sciences, 2016, 5, 1537-1543.

7. F. H. Do Monte, J. G. Dos Santos, M. Russi, V. M. Lanziotti, L. K. Leal and G. M. Cunha, Antinociceptive and anti-inflammatory properties of the hydroalcoholic extract of stems from Equisetum arvense $L$. in mice, Pharmacology Research, 2004, 49, 239- 243.

8. K. Joshi, R. Joshi and A. R. Joshi, Indigenous knowledge and uses of medicinal plants in Macchegaun, Nepal, Indian Journal of traditional knowledge, 2011, 10, 281- 286.

9. S. S. Ghori, M. I. Ahmed, M. Arifuddin and M. S. Khateeb, Evaluation of analgesic and antiinflammatory activities of formulation containing camphor, menthol and thymol, International Journal of Pharmacy \& Pharmaceutical Science, 2016, 8, 271-274. 